\title{
Tratamento de efluentes de postos de combustíveis para o reúso usando processos oxidativos avançados
}

\section{Treatment of effluent of fuel ranks for $i$ reuse it using advanced processes oxidativos}

\section{Daniela V. Vasconcelos ${ }^{1}$ Anderson Gomes ${ }^{2}$}

\section{Palavras-chaves: \\ Processos oxidativos \\ Peróxido de hidrogênio \\ Ultravioleta}

Reuso de água

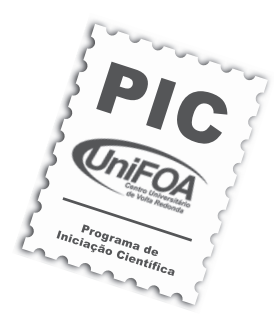

Resumo

Buscando pesquisar processos alternativos para o tratamento de efluentes, este trabalho estudou a aplicação de um processo oxidativo avançado, POA, $\left(\mathrm{H}_{2} \mathrm{O}_{2} / \mathrm{UV}\right)$, para o tratamento de um efluente originado de lavagens de carros para fins de reúso com o objetivo de reduzir o valor inicial de cor aparente, turbidez, condutividade, demanda química de oxigênio (DQO), óleos e graxas, amônia, sólidos suspensos, dissolvidos, surfactantes, verificando se a qualidade final da água para que ela possa ser reutilizada nas lavagens. Soluções do efluente foram submetidas ao tratamento proposto, utilizando-se um reator comercial com lâmpada de luz ultravioleta com volume útil de $350 \mathrm{~mL}$. Foram estudadas diferentes concentrações de peróxido de hidrogênio em diferentes pH's. Pelos resultados obtidos no presente estudo, observou-se que o $\mathrm{POA}_{2} \mathrm{O}_{2} / \mathrm{UV}$ é um processo de tratamento que pode ser aplicado no tratamento do efluente das lavagens de carros em postos de combustíveis.

\section{Abstract}

Seeking find alternative processes for the treatment of effluents, this paper studied the application of an advanced oxidative process, POA, $\left(\mathrm{H}_{2} \mathrm{O}_{2} / \mathrm{UV}\right)$ for the treatment of effluent originated from a car wash for reuse with the objective of reducing the initial value of apparent color, turbidity, conductivity, chemical oxygen demand (COD), oils and grease, ammonia, suspended solids, dissolved, surfactant, whether the final quality of water so that it can be reused in the wash. The effluent solutions were proposed to treatment using a commercial reactor with ultraviolet light lamp and volume of $350 \mathrm{~mL}$. We studied different concentrations of hydrogen peroxide at different $\mathrm{pH}$ 's. The results obtained in this study, we observed that $\mathrm{POA} \mathrm{H}_{2} \mathrm{O}_{2} / \mathrm{UV}$, is a process of treatment that can be applied in the treatment of effluent from washing of cars on the station fuel.
Key words:

Oxidative processes

Hydrogen peroxide

Ultraviolet

Reuse of water

\section{Introdução}

A água é um recurso natural de valor inestimável. Mais que um insumo indispensável à produção e um recurso estratégico para o desenvolvimento econômico, ela é vital para a manutenção dos ciclos biológicos, geológicos e químicos que mantêm em equilíbrio os ecossistemas. É, ainda, uma referência cultural e um bem social indispensável à adequada qualidade de vida da população.
Artigo

Original

Original

Paper

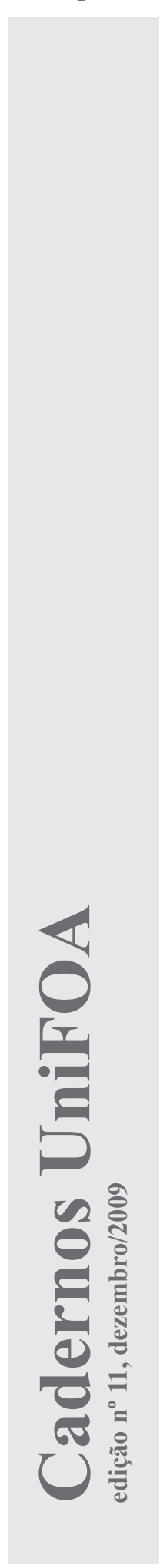

Discente do Curso de Engenharia Ambiental - UniFOA

${ }^{2}$ Mestrando e Docente do Curso de Engenharia Ambiental - UniFOA 
Depois de ser utilizada, a água é restituída ao seu ambiente natural e a mesma não deve comprometer os possíveis usos que podem ser feitos, tanto públicos como privados. A contaminação é uma modificação da qualidade da água, provocada, geralmente, pelo homem, de tal forma a torná-la inapta ou danosa ao consumo homano, à indústria, à agricultura, à pesca, às atividades recreativas, aos animais domésticos e aos selvagens. O reuso da água se tornou um item estratégico na gestão de recursos hídricos, pois pode substituir a água potável por uma água de qualidade inferior, causando a redução na demanda sobre os mananciais.

No Brasil existem muitos postos de combustível e grande parte deles oferece o serviço de lavagem de automóveis. A água destinada a esse fim, de um modo geral, é a mesma destinada ao consumo da população, com grandes custos de tratamento. Por outro lado, os efluentes gerados nessa atividade estão contaminados principalmente por óleos, graxas, sabões e material argiloso em suspensão que recebem em alguns casos apenas o tratamento preliminar.

É desejável, às vezes obrigatório, reaproveitar a água durante a operação de lavagens de veículos, dependerá da legislação municipal.

O tratamento dessa água com o sistema Ultravioleta é uma maneira ambientalmente amigável de desinfetar a água e descartála para rios, áreas da costa, corpos de água e etc. Conhecido também como um processo de oxidação química, é uma opção a ser escolhida, pois pode ser utilizado em várias ocasiões, como remoção da cor, controle de gosto e odor, redução de compostos orgânicos específicos, precipitação de metais e destruição de microorganismos, entre outras remoções. Os principais oxidantes químicos que podem ser empregados nesse processo são: Cloro, Hipocloritos, Cloroaminas, Dióxido de cloro; Permanganato de potássio, Ozônio e Peróxido de Hidrogênio.

O reuso de água é parte de uma atividade mais abrangente que é o uso racional ou eficiente da água, o qual compreende também o controle de perdas e desperdícios, e a minimização da produção de efluentes e do consumo de água.

Dentro dessa ótica, os esgotos tratados têm um papel fundamental no planejamento e na gestão sustentável dos recursos hídricos como um substituto para o uso de águas destinadas a fins agrícolas e de irrigação, entre outros.
Ao liberar as fontes de água de boa qualidade para abastecimento público e outros usos prioritários, o uso de esgotos contribui para a conservação dos recursos e acrescenta uma dimensão econômica ao planejamento dos recursos hídricos. O reuso reduz a demanda sobre os mananciais de água devido à substituição da água potável por uma água de qualidade inferior. Essa prática, atualmente muito discutida - posta em evidência - e já utilizada em alguns países, é baseada no conceito de substituição de mananciais. Tal substituição é possível em função da qualidade requerida para um uso específico.

Dessa forma, grandes volumes de água potável podem ser poupados pelo reuso quando se utiliza água de qualidade inferior (geralmente efluentes pós-tratados) para atendimento das finalidades que podem prescindir desse recurso dentro dos padrões de potabilidade.

Os critério de seleção e do tipo e grau de tratamento estão também relacionados às exigências da legislação ambiental, cuja peça fundamental, no âmbito federal, no Brasil, é a lei 6938 de 31 de agosto de 1981, que institui a Política Nacional do Meio Ambiente (PNMA). De acordo com a PNMA, seus principais instrumentos são:

- O estabelecimento de padrões de qualidade ambiental

- A avaliação de impactos ambientais

- O licenciamento de atividades poluidoras

Esses instrumentos legais objetivam que os lançamentos dos esgotos tratados nos corpos d água consideram e preservam:

\section{- $\quad \mathrm{O}$ aspecto estético}

- A vida aquática

- A saúde publica

As legislações federais que incorporam esses conceitos são: CONAMA 357 de 17 de março de 2005, que dispõe sobre a classificação dos corpos de água e diretrizes ambientais para o seu enquadramento, bem como estabelece as condições e padrões de lançamen- 
to de efluentes; Portaria 518 do Ministério da Saúde de 25 de março de 2004, que estabelece os procedimentos e responsabilidades relativas ao controle e vigilância da qualidade da água para consumo humano e seu padrão de potabilidade. Também há a legislação estadual do Rio de Janeiro elaborada pela CECA (Comissão Estadual de Controle Ambiental) a NT 202 de 04 de dezembro de 1986 que estabelece critérios e padrões para o lançamento de efluentes líquidos.

\section{Sistema de tratamento existente}

O tratamento que é utilizado pelo posto é somente o gradeamento para reter sólidos grosseiros, passando pela caixa de areia para que os sólidos em suspensão se depositem no fundo e, por último, a água de lavagem chega ao separador água/óleo retendo óleos livres, lançando o efluente na rede pública de água e esgoto, conforme fluxo da figura 1.

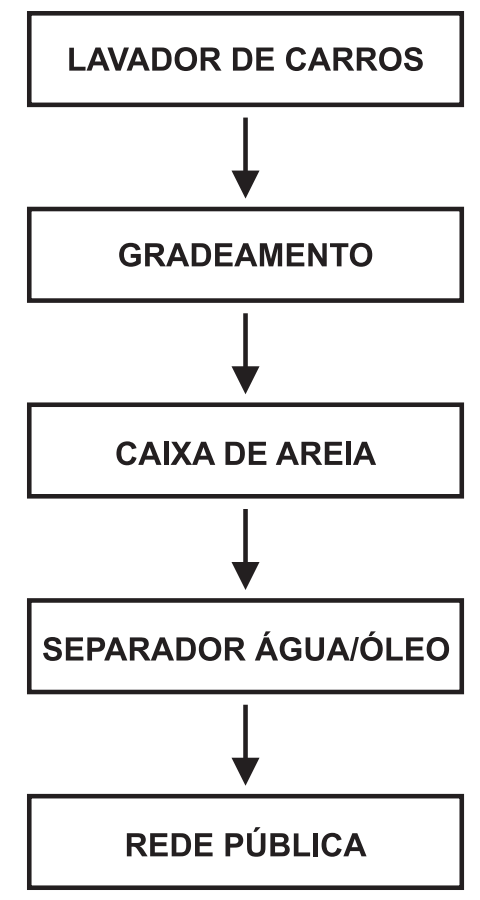

Figura 1 - Fluxograma do Sistema Atual

\section{Definições dos principais parâ- metros a serem monitorados}

\subsection{Turbidez}

A turbidez das águas é em razão da presença de partículas em suspensão, ela pode ser causada por uma grande variedade de materiais, incluindo partículas de areia fina, silte, argila e micro-organismos. A presença dessas partículas provoca a dispersão e a absorção da luz, dando a água uma aparência nebulosa.

A turbidez é avaliada a partir da medida da quantidade de luz refletida, dando a ordem de grandeza dos sólidos em suspensão na amostra, mas não pode ser associada de imediato a quantidade de sólidos e é determinada através do turbidímetro, após realizada a homogeneização da amostra e a calibração do aparelho.

\subsection{Cor}

A água pura é virtualmente ausente de cor. A presença de substâncias dissolvidas ou em suspensão altera a cor da água, dependendo da quantidade e natureza do material presente. A cor é sensível ao $\mathrm{pH}$ e a sua remoção é mais fácil a $\mathrm{pH}$ baixo. Ao contrário, quanto maior o $\mathrm{pH}$, mais intensa é a cor.

A cor de uma amostra de água está associada ao grau de redução de intensidade que a luz sofre ao atravessá-la (e essa redução dá-se por absorção de parte da radiação eletromagnética). Dentre os coloides orgânicos, pode-se mencionar os ácidos húmico e fúlvico, substâncias naturais resultantes da decomposição parcial de compostos orgânicos presentes em folhas, dentre outros substratos. Também os esgotos sanitários se caracterizam por apresentarem predominantemente matéria em estado coloidal, além de diversos efluentes industriais contendo taninos (efluentes de curtumes, por exemplo), anilinas (efluentes de indústrias têxteis, indústrias de pigmentos, etc.), lignina e celulose (efluentes de indústrias de celulose e papel, da madeira, etc.). O problema maior de coloração na água, em geral, é o estético já que causa um efeito repulsivo aos consumidores.

\section{3. Óleos e Graxas}

Óleos e graxas, de acordo com o procedimento analítico empregado, consistem no conjunto de substâncias que, em determinado solvente, consegue extrair da amostra e que não se volatiliza durante a evaporação do solvente a $100^{\circ} \mathrm{C}$. Essas substâncias, ditas solúveis em n-hexano, compreendem ácidos graxos, gorduras animais, sabões, graxas, óle-

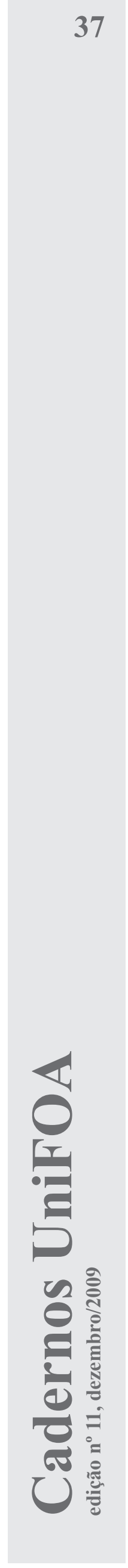


os vegetais, ceras, óleos minerais, etc. Esse parâmetro costuma ser identificado também por MSH - material solúvel em hexano.

Os óleos e graxas são substâncias orgânicas de origem mineral, vegetal ou animal e estas substâncias geralmente são hidrocarbonetos, gorduras, ésteres, entre outros. São raramente encontrados em águas naturais, normalmente oriundos de despejos e resíduos industriais, esgotos domésticos, efluentes de oficinas mecânicas, postos de gasolina, estradas e vias públicas.

Os despejos de origem industrial são os que mais contribuem para o aumento de matérias graxas nos corpos d'água. Dentre os despejos, podemos citar os de refinarias, frigoríficos, saboarias, etc. A pequena solubilidade dos óleos e graxas constitui um fator negativo no que se refere à sua degradação em unidades de tratamento de despejos por processos biológicos e, quando presentes em mananciais utilizados para abastecimento público, causam problemas no tratamento d'água. A presença de material graxo nos corpos d'água, além de acarretar problemas de origem estética, diminui a área de contato entre a superfície da água e o ar atmosférico, impedindo, dessa maneira, a transferência do oxigênio da atmosfera para a água.

Os óleos e graxas, em seu processo de decomposição, reduzem o oxigênio dissolvido, elevando a $\mathrm{DBO}_{5}$ e a DQO, causando alteração no ecossistema aquático. Na legislação brasileira, não existe limite estabelecido para esse parâmetro; a recomendação é de que os óleos e as graxas sejam virtualmente ausentes para as classes 1, 2 e 3 de águas doces, da CONAMA 357.

\section{4. $\mathrm{pH}$}

$\mathrm{O} \mathrm{pH}$ é utilizado para expressar a acidez de uma solução. Trata-se de um parâmetro importante, principalmente nas etapas de coagulação, filtração, desinfecção e controle de corrosão.

\subsection{Sólidos}

Sólidos nas águas correspondem a toda matéria que permanece como resíduo, após evaporação, secagem ou calcinação da amostra a uma temperatura pré-estabelecida durante um tempo fixado. Em linhas gerais, as ope- rações de secagem, calcinação e filtração são as que definem as diversas frações de sólidos presentes na água (sólidos totais, em suspensão, dissolvidos, fixos e voláteis).

No controle operacional de sistemas de tratamento de esgotos, algumas frações de sólidos assumem grande importância. Em processos biológicos aeróbios, como os sistemas de lodos ativados e de lagoas aeradas mecanicamente, bem como em processos anaeróbios, as concentrações de sólidos em suspensão voláteis nos lodos dos reatores tem sido utilizadas para se estimar a concentração de microrganismos decompositores da matéria orgânica.

Para o recurso hídrico, os sólidos podem causar danos aos peixes e à vida aquática. Eles podem se sedimentar no leito dos rios, destruindo organismos que fornecem alimentos, ou também danificar os leitos de desova de peixes. Os sólidos podem reter bactérias e resíduos orgânicos no fundo dos rios, promovendo decomposição anaeróbia. Altos teores de sais minerais, particularmente sulfato e cloreto, estão associados à tendência de corrosão em sistemas de distribuição, além de conferir sabor às águas.

\subsection{DQO e DBO}

É a quantidade de oxigênio necessária para oxidação da matéria orgânica através de um agente químico. Os valores da DQO, normalmente, são maiores que os da $\mathrm{DBO}_{5^{2} 20}$, sendo o teste realizado num prazo menor. $\mathrm{O}$ aumento da concentração de DQO num corpo d'água se deve principalmente a despejos de origem industrial.

A DQO é um parâmetro indispensável nos estudos de caracterização de esgotos sanitários e de efluentes industriais. A DQO é muito útil quando utilizada conjuntamente com a $\mathrm{DBO}_{5,20}$ para observar a biodegradabilidade de despejos. Sabe-se que o poder de oxidação do dicromato de potássio é maior do que o que resulta mediante a ação de micro-organismos, exceto raríssimos casos como hidrocarbonetos aromáticos e piridina. Dessa forma, os resultados da DQO de uma amostra são superiores aos de $\mathrm{DBO}_{5,20}$. Como na $\mathrm{DBO}_{5,20}$ mede-se apenas a fração biodegradável, quanto mais esse valor se aproximar da DQO significa que mais facilmente biodegradável será o efluente. 
A DQO tem se demonstrado um parâmetro bastante eficiente no controle de sistemas de tratamentos anaeróbios de esgotos sanitários e de efluentes industriais.

\subsection{Surfactantes}

Analiticamente, detergentes ou surfactantes são definidos como compostos que reagem com o azul de metileno sob certas condições especificas. Esses compostos são designados "substâncias ativas ao azul de metileno" e suas concentrações são relativas ao sulfonato de alquil benzeno linear (LAS) que é utilizado como padrão na análise.

Detergentes nas águas naturais levam a prejuízos de ordem estética provocados pela formação de espumas, além disso, os detergentes podem exercer efeitos tóxicos sobre os ecossistemas aquáticos. Os sulfonatos de alquil benzeno de cadeia linear (LAS) têm substituído progressivamente os sulfonatos de aquil benzeno de cadeia ramificada (ABS), por serem considerados biodegradáveis. Os testes de toxicidade têm sido mais bem desenvolvidos e há certa tendência em passarem a ser mais utilizados nos programas de controle de poluição.

Os detergentes têm sido responsabilizados também pela aceleração da eutrofização. Além de a maioria dos detergentes comerciais empregados ser rica em fósforo, sabe-se que exerce efeito tóxico sobre o zooplâncton, predador natural das algas. Segundo esse conceito, não bastaria apenas a substituição dos detergentes superfosfatados para o controle da eutrofização.

\subsection{Ferro}

O ferro aparece principalmente em águas subterrâneas devido à dissolução do minério pelo gás carbônico da água, conforme a reação:

$$
\mathrm{Fe}+\mathrm{CO}_{2}+1 / 2 \mathrm{O}_{2} \rightarrow \mathrm{FeCO}_{3}
$$

O carbonato ferroso é solúvel e frequentemente é encontrado em águas de poços contendo elevados níveis de concentração de ferro. Nas águas superficiais, o nível de ferro aumenta nas estações chuvosas devido ao carreamento de solos e a ocorrência de processos de erosão das margens. Também poderá ser importante a contribuição devida a efluentes industriais, pois muitas indústrias metalúrgicas desenvolvem atividades de remoção da camada oxidada (ferrugem) das peças antes de seu uso, processo conhecido por decapagem, que normalmente é procedida através da passagem da peça em banho ácido.

$\mathrm{O}$ ferro, apesar de não se constituir em um tóxico, traz diversos problemas para o abastecimento público de água. Confere cor e sabor à água, provocando manchas em roupas e utensílios sanitários. Também traz o problema do desenvolvimento de depósitos em canalizações e de ferro-bactérias, provocando a contaminação biológica da água na própria rede de distribuição. Por esses motivos, o ferro constitui-se em padrão de potabilidade, tendo sido estabelecida a concentração limite de $0,3 \mathrm{mg} / \mathrm{L}$ na Portaria 1469 do Ministério da Saúde. É também padrão de emissão de esgotos e de classificação das águas naturais.

\section{A Radiação Ultravioleta}

A radiação ultravioleta pertence ao espectro eletromagnético e está situada na faixa de 40 a $400 \mathrm{~nm}$ de comprimento de onda, entre os raios-X e a luz visível, que pode ser dividida em (SOBOTKA, 1993):

$$
\begin{aligned}
& \text { - } \quad \text { UV vácuo - } 40 \text { a } 200 \text { nm; } \\
& \text { - } \quad \text { UV C - } 200 \text { a } 280 \text { nm; } \\
& \text { - } \quad \text { UV B - } 280 \text { a } 315 \text { nm; } \\
& \text { - } \quad \text { UV A - } 315 \text { a } 400 \text { nm; }
\end{aligned}
$$

Segundo ALAN e DONAIRE (2001), a irradiação UV pode ser usada sozinha e com muito sucesso na inativação de algas e na inativação de micro-organismos patogênicos , pois ela causa um dano no seu DNA, impedindo sua reprodução. Além disso, a radiação UV pode ser usada na destruição de compostos orgânicos em processos de degradação fotoquímicos e fotocatalíticos. Os radicais hidroxila, que são as espécies oxidantes nesses processos, podem ser gerados através da utilização de oxidantes, como ozônio, peróxido de hidrogênio, Fenton, etc, sem irradiação UV. Entretanto, o uso combinado desses oxidantes com UV tem uma série de vantagens, aumentando a eficiência dos processos catalíticos. 
A irradiação UV é um parâmetro de extrema importância nos processos fotomediados, entretanto, as lâmpadas utilizadas têm uma vida útil, que pode variar em função de vários fatores, como por exemplo: o composto que está sendo tratado, pois, dependendo da sua natureza, ele pode atacar a superfície da lâmpada. Assim, deve-se ter certeza de que sua eficiência, medida pela intensidade luminosa está garantida, pois, do contrário, o processo pode ser afetado. A intensidade luminosa pode ser medida pelo uso de actinômetros químicos, como oxalato de potássio, entretanto, as lâmpadas mais modernas já vêm acopladas a um sistema que faz esta medida automática e ininterruptamente.

\subsection{Fotólise direta com ultravioleta (UV)}

A luz é a única fonte capaz de produzir a destruição do poluente. A fotólise direta, em comparação com processos envolvendo geração de radicais hidroxila, tem, geralmente, uma eficiência mais baixa. Assim, a maioria dos estudos é feita para quantificar a contribuição da fotólise da matéria orgânica em processos de oxidação em que ela atua de forma conjunta, por exemplo: $\mathrm{H}_{2} \mathrm{O}_{2} / \mathrm{UV}, \mathrm{O}_{3} / \mathrm{UV}$ e $\mathrm{H}_{2} \mathrm{O}_{2} /$ $\mathrm{O}_{3} / \mathrm{UV}$. Além da aplicabilidade na degradação de poluentes, a irradiação pode ser utilizada para outros fins.

\subsection{A fonte luminosa}

Ao lado dos parâmetros mencionados anteriormente, características de emissão e geometria da fonte luminosa são fatores decisivos para o projeto de um reator fotoquímico. As fontes luminosas podem ser naturais ou artificiais. Além disso, entre as artificiais, as fontes luminosas podem ser de baixa e média pressão, ou mesmo de tipos de lâmpadas diferentes, como a germicida e a luz negra.

\section{Peróxido de Hidrogênio $\mathrm{H}_{2} \mathrm{O}_{2}$}

$\mathrm{O}$ uso de $\mathrm{H}_{2} \mathrm{O}_{2}$, o segundo oxidante auxiliar mais utilizado, também apresenta algumas vantagens: capacidade de oxidar diretamente alguns compostos, solubilidade em água, geração de dois radicais $\bullet \mathrm{OH}$ por molécula de $\mathrm{H}$ fotolisada, estabilidade térmica, procedimentos de operação simples, possibilidade de estoque no local, inexistência de problemas de transferência de massa e, na fotocatálise heterogênea, é capaz de gerar radicais hidroxila tanto com as lacunas quanto com os elétrons. Entretanto, possui algumas desvantagens: a taxa de oxidação química do poluente é limitada pela taxa de formação dos radicais hidroxila e é dependente da matéria orgânica presente e da quantidade de oxidante adicionado ao sistema. Além disso, tem sido sugerido que $\mathrm{o}_{2} \mathrm{O}_{2}$ funciona como um receptor de radicais hidroxila.

\subsection{Peróxido de Hidrogênio +} Ultra-violeta $\left(\mathrm{H}_{2} \mathrm{O}_{2}+\mathrm{UV}\right)$

O processo que combina o peróxido de hidrogênio com irradiação ultravioleta é muito mais eficiente do que o uso de cada um deles separadamente. Isso ocorre pela grande produção de radicais hidroxila, que são altamente oxidantes.

Segundo HUANG i (1993) e LEGRINI (1993), o mecanismo mais comumente aceito para a fotólise de $\mathrm{H}_{2} \mathrm{O}_{2}$ com UV, é a quebra da molécula em radicais hidroxila com um rendimento de dois $\bullet \mathrm{OH}$ para cada molécula de $\mathrm{H}_{2} \mathrm{O}$, mas é bom lembrar que também existe a possibilidade de recombinação desses radicais, transformando-se em $\mathrm{H}_{2} \mathrm{O}_{2}$.

\section{Metodologia}

\subsection{Parâmetros analisados}

Todos os procedimentos utilizados tiveram como referência o Manual do Meio Ambiente: Métodos FEEMA e as amostras foram coletadas no lava a jato do posto, na cidade de Valença/RJ. O efluente foi coletado antes do tratamento executado pelo posto, ou seja, foi coletado o efluente bruto e as análises foram realizadas no laboratório do Centro Universitário de Volta Redonda (UniFOA), sendo elas:

a) Determinação de Turbidez - MF-435.R-1

b) Determinação de Cor - MF-434.R-1

c) Determinação de Surfactantes - MF417.R-1

d) Determinação de Resíduos Sedimentáveis - MF-0416.R-0 
e) Determinação de Resíduos Filtráveis, Fixo e Volátil - MF-0436.R-1

f) Determinação da Demanda Química de Oxigênio - MF-0440.R-3

g) Determinação de Nitrogênio Amoniacal MF-420.R-3

h) Determinação de Óleos e Graxas - MF413.R-1

i) Determinação de Ferro - MF.465.R-1

\subsection{Memorial de Cálculo}

\subsubsection{Caracterização do efluente:}

a) Vazão: A vazão média do lavador do posto de gasolina foi efetuada medições do tempo de lavagem dos carros, obtendo os valores demonstrados na tabela 1 .

\begin{tabular}{c|c|c} 
& Mangueira & Máquina \\
\hline $\begin{array}{c}\text { Tempo de } \\
\text { Enchimento } \\
\text { de 2 Litros }\end{array}$ & $9,16 \mathrm{~s}$ & $28,54 \mathrm{~s}$ \\
\hline $\begin{array}{c}\text { Tempo de } \\
\text { Lavagem de } \\
\text { Veículo 1 }\end{array}$ & $249 \mathrm{~s}$ & $93 \mathrm{~s}$ \\
\hline $\begin{array}{c}\text { Tempo de } \\
\text { Lavagem de } \\
\text { Veículo 2 }\end{array}$ & $187 \mathrm{~s}$ & $99 \mathrm{~s}$ \\
\hline $\begin{array}{c}\text { Tempo de } \\
\text { Lavagem de } \\
\text { Veículo 3 }\end{array}$ & $207 \mathrm{~s}$ & $103 \mathrm{~s}$
\end{tabular}

Tabela 1 - Tempo necessário para a lavagem de um carro

$$
\mathrm{C}=\mathbf{3 0} \text { carros/dia }
$$

Tempo total médio gasto com mangueira

$$
=214,33 \mathrm{~s} / \text { carro }
$$

Tempo total médio gasto com a máquina

$$
=98,33 \mathrm{~s} / \text { carro }
$$

Se para encher $2 \mathrm{~L}$ de água a mangueira levou 9,16 segundos, para lavar um carro leva 214,33 segundos e gasta 46,80 litros de água. Cada orifício da máquina leva 28,54 segundo para encher 2 litros de água, como a máquina possui 20 orifícios, leva em média 98,33 segundos para lavar um carro, e como os orifícios esguicham água ao mesmo tempo, cada orifício leva 98,33 segundos para lavar o carro.
Se 28,54 segundos enche 2 litros, 98,33 segundos enchem 6,89 litros cada orifício.

Juntando-se os 20 orifícios tem-se o gasto total de água por carro que é igual a 137,8 litros.

$$
\begin{gathered}
\text { Gasto Total de água } \\
=\mathbf{5 9 , 6 1}+\mathbf{1 3 6 , 6}=\mathbf{1 9 6 , 2 1} \mathrm{L}
\end{gathered}
$$

$$
\text { Tempo total }=\mathbf{3 7 0 , 5} \mathrm{s}
$$

\section{Se o lavador lava em média 30 carros} por dia, a vazão será 5886,3 L/dia

A água gasta na lavagem com a máquina independe do tamanho do carro, pois o tempo sempre será o mesmo, pois a máquina percorre sempre o mesmo percurso esguichando água sobre o carro, já na lavagem com a mangueira depende do estado do carro, pois é manuseada pelo funcionário, é uma pré-lavagem, pois a máquina não retira sujeiras grossas.

b) Análise química: Foi feita a caracterização química do efluente do lavador do posto de gasolina, obtendo os valores demonstrados na tabela 2 .

\begin{tabular}{c|c|c} 
& $\begin{array}{c}\text { Amostra } \\
\text { Bruta }\end{array}$ & $\begin{array}{c}\text { Amostra } \\
\text { Decantada }\end{array}$ \\
\hline DQO & 12130 & 350 \\
\hline Ferro & 976,1 & 62,8 \\
\hline Óleos e Graxas & 164,52 & 30,96 \\
\hline Surfactantes & 1,69 & 1,61 \\
\hline Amônia & 1,04 & 1,03 \\
\hline Cor & 470 & 462 \\
\hline Turbidez & 538 & 327
\end{tabular}

Tabela 2 - Caracterização do Efluente Bruto e Decantado

Como o efluente a ser tratado será coletado após o tanque de decantação a concentração de DQO a ser adotada para o dimensionamento será $350 \mathrm{mg} / \mathrm{L}$ 
6.2.2. Determinação do Volume de Peróxido de Hidrogênio adicionado ao efluente

Segundo POLEZI (2003), a reação genérica para a redução de $\mathrm{DBO} / \mathrm{DQO}$ pode ser expressa como:

$$
\mathrm{DBO} / \mathrm{DQO}+2 \mathrm{H}_{2} \mathrm{O}_{2} \rightarrow \mathrm{CO}_{2}+\mathrm{H}_{2} \mathrm{O}
$$

Para a DQO de $350 \mathrm{mg} / \mathrm{L}$ será necessário uma concentração de $700 \mathrm{mg} / \mathrm{L}$ de $\mathrm{H}_{2} \mathrm{O}_{2}$.

$$
\mathrm{DQO}=350 \mathrm{mg} / \mathrm{L} \times 2=700 \mathrm{mg} / \mathrm{L} \text { de } \mathrm{H}_{2} \mathrm{O}_{2}
$$

Como o peróxido de hidrogênio comercial encontra-se numa concentração a $30 \%$ e uma densidade de $1,11 \mathrm{~g} / \mathrm{cm} 3$, será necessário corrigir a quantidade a ser adicionada durante o teste:

Correção da concentração:

$700 \mathrm{mg}-100 \%$

$\mathrm{X} \operatorname{mg}-30 \% \quad \mathrm{X}=2333,33 \mathrm{mg}$

Correção da densidade:

$$
\begin{gathered}
\mathrm{d}=\mathrm{m} / \mathrm{V} \\
1,11=2333,33 / \mathrm{V} \\
\mathrm{V}=2102,1 \\
\mathrm{~V}=2,1 \mathrm{~mL}
\end{gathered}
$$

Será adicionado 2,1 mL de $\mathrm{H}_{2} \mathrm{O}_{2}$ por litro de efluente a ser tratado. Como o ensaio será realizado em Jar-test, e este possui um jarro de volume 2L, será necessário corrigir a adição.

\section{Para $2 \mathrm{~L}=4,2 \mathrm{~mL}$}

\subsubsection{Determinação da vazão da bomba}

Foram feitas 3 medições de volumes de 2 L em proveta graduada classe A e determinado o tempo de enchimento desta proveta, apresentado um tempo médio de 69,24 segundos, perfazendo uma vazão média de $28,9 \mathrm{~mL} / \mathrm{s}$.
6.2.4. Determinação do tempo de detenção hidráulica dentro do reator de UV.

Como a câmara do reator de UV apresenta um volume de $350 \mathrm{~mL}$ e a vazão média da bomba é $28,9 \mathrm{~mL} / \mathrm{s}$, tem-se um tempo de detenção hidráulica de 12,11 segundos.

$$
350 / 28,9=\mathbf{1 2 , 1 1} s
$$

\subsection{Ensaio de Jar-Test}

O ensaio no aparelho de jar-test seguiu as seguintes etapas:

a) Adicionar 2 litros da amostra de água com o auxílio de uma proveta, a cada um dos 6 vasos do aparelho de jar-test.

b) Deixar as amostras sob agitação durante 30 segundos a $100 \mathrm{rpm}$ e, em seguida, baixar a velocidade para $\pm 25 \mathrm{rpm}$.

c) Desligar os agitadores após 15 minutos de agitação e retirar uma amostra para análise. Bombear $350 \mathrm{~mL}$ do efluente para o sistema UV. Deixar o efluente no sistema por 12,1 segundos, após esse tempo retirar uma amostra para análise.

d) No vaso 2, adicionar 4,2 $\mathrm{mL}$ de peróxido de hidrogênio e ácido sulfúrico até $\mathrm{pH} 2$, tirar uma amostra para análise. Bombear $350 \mathrm{~mL}$ desse efluente para a o sistema UV, deixar por 12,1 segundos, retirar uma amostra para análise;

g) No vaso 3 , adicionar $4,2 \mathrm{~mL}$ de peróxido de hidrogênio e ácido sulfúrico até $\mathrm{pH} 4$, retirar uma amostra para análise. Bombear $350 \mathrm{~mL}$ desse efluente para a o sistema $\mathrm{UV}$, deixar por 12,1 segundos, retirar uma amostra para análise;

i) No vaso 4 , adicionar $2,1 \mathrm{~mL}$ de peróxido de hidrogênio,retirar uma amostra para análise. Bombear 350mL desse efluente para a o sistema UV, deixar por 12,1 segundos, retirar uma amostra para análise;

k) No vaso 5 , adicionar $2,1 \mathrm{~mL}$ de peróxido de hidrogênio e ácido sulfúrico até pH 2, 
retirar uma amostra para análise. Bombear $350 \mathrm{~mL}$ desse efluente para a o sistema $\mathrm{UV}$, deixar por 12,1 segundos, retirar uma amostra para análise;

m) No vaso 6 , adicionar $2,1 \mathrm{~mL}$ de peróxido de hidrogênio e ácido sulfúrico até $\mathrm{pH} 4$, retirar uma amostra para análise. Bombear $350 \mathrm{~mL}$ desse efluente para a o sistema UV, deixar por 12,1 segundos, retirar uma amostra para análise;

\section{Sugestões e Conclusão}

\section{1 Sugestão de Tratamentos Físicos}

Segundo JORDÃO, o funcionamento de uma Estação de Tratamento de Efluente (ETE) compreende basicamente as seguintes etapas e segue o fluxo conforme figura 2 :

\subsubsection{Gradeamento}

As grades servirão para impedir que sólidos grosseiros passem, como, por exemplo, folhas de árvores. Esse equipamento terá a função de garantir o funcionamento dos equipamentos a jusante.

\subsubsection{Caixa de areia}

A caixa de areia irá retirar do efluente toda a areia resultante da lavagem de carros, essa areia é oriunda de diversos processos, pois os carros podem tê-la obtido de várias formas, como, por exemplo, por ter passado em estradas de terra, o que é muito comum no município onde se localiza o lavador.

\subsubsection{Separador Água/Óleo}

As caixas separadores de óleos e graxas são designadas especialmente para remover óleo que está flutuante, gasolina, compostos de petróleo leves e graxas. O separador água/óleo retirará todo o óleo livre, contido no efluente, que é oriundo de vazamentos dos carros a serem lavados e também encontrados vestígios nos demais carros.
Esse tanque receberá o efluente do separador o água/óleo

\subsubsection{Bomba}

A bomba servirá para bombear o efluente para o filtro de areia.

\subsubsection{Filtro de Areia}

A filtração da água consiste em fazê-la passar através de substâncias porosas capazes de reter ou remover algumas de suas impurezas, a filtração lenta, por sua vez, atua na redução de parâmetros de qualidade, como cor, turbidez, sólidos suspensos e coliformes.

\subsubsection{Filtro de Carvão Ativado}

Os filtros de carvão ativado possuem leito granulado fixo, cuja área superficial é bastante elevada, fazendo com que o material possua grande poder de adsorção de compostos presentes no efluente vindo do filtro de areia. O objetivo deste equipamento é adsorver compostos odorizantes e colorantes dos efluentes do filtro de areia.

\subsubsection{Medidor de Vazão}

O medidor de vazão atuará na mistura do peróxido de hidrogênio e o ácido sulfúrico com o efluente e ajudará na medição e amostragem de efluente tratado.

\subsubsection{Tanque de Exposição à Ultra Violeta}

O tanque receberá o efluente contendo peróxido de hidrogênio e em $\mathrm{pH}$ ácido, e ficará em exposição a luz ultra violeta que fará a oxidação e removerá parte dos parâmetros.

\subsubsection{Tanque de Neutralização}

Receberá o efluente com $\mathrm{pH} 2$ e fará o controle através da adição de uma base, o hidróxido de sódio $(\mathrm{NaOH})$.

\subsubsection{Tanque de Reuso}


Esse tanque receberá o efluente devidamente tratado com $\mathrm{pH}$ neutralizado, ou seja, próximo de 7 , e o distribuirá, $70 \%$ do efluente tratado seguirá para o tanque de armazenamento e os outros 30\% serão lançados na rede pública de água e esgoto.

\subsubsection{Reservatório de Armazenamento}

O tanque receberá $70 \%$ do efluente tratado. Esse efluente ficará no tanque e será bombeado para o lavador, onde será reutilizado em novas lavagens.

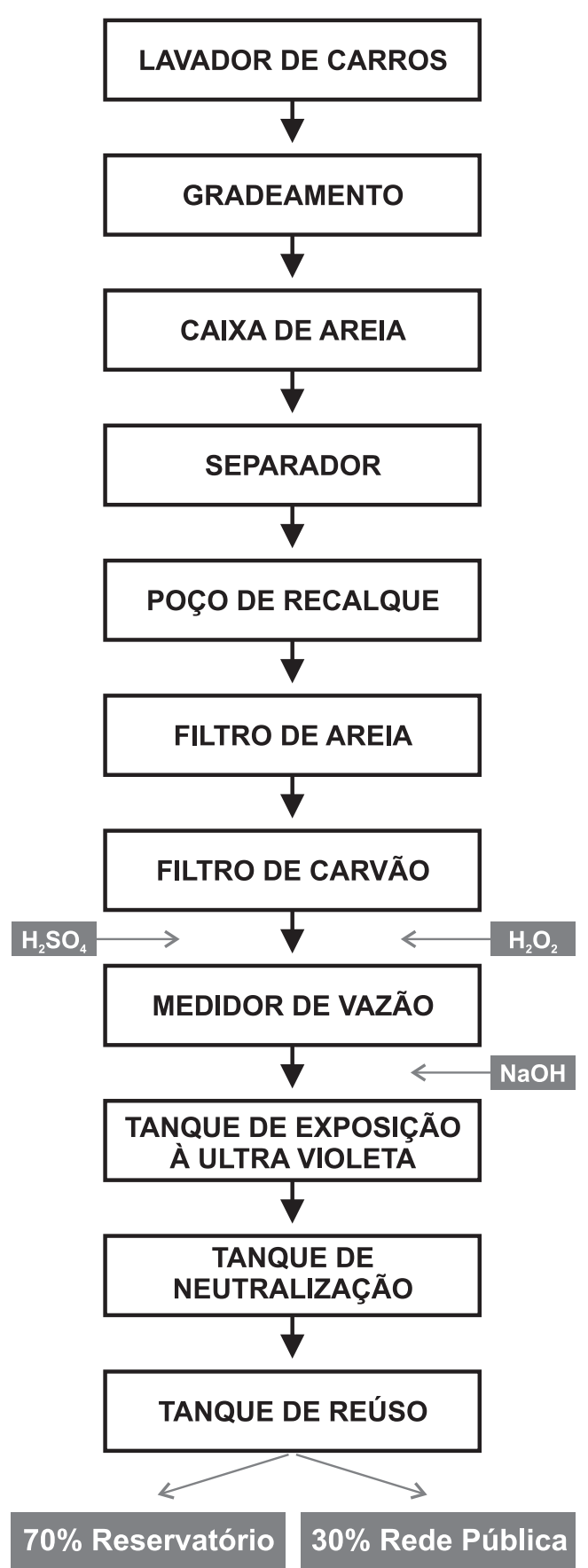

Figura 2- Diagrama de blocos do tratamento proposto.

\subsection{Conclusão}

É viável o reuso da água de lavagem de veículos em um posto de gasolina, quando o mesmo sofre tratamento, os resultados obtidos nos testes de bancada, utilizando um efluente de um posto de combustível, mostrou que é possível obter uma água de boa qualidade através de processos oxidativos avançados, conforme mostrado na tabela 4 (ver anexo 1), que compara os resultados dos ensaios efetuados com a adição de peróxido e ultra violeta com a especificação da água na CONAMA 356 e NT 202 - R10.

Os melhores resultados obtidos no tratamento da água por processos oxidativo, deuse no Teste 4, ajustando o efluente a pH 2,0, com adição de $700 \mathrm{mg} / \mathrm{L}$ de peróxido de hidrogênio e passagem pela câmara de UV, nessas condições, conseguiu-se a melhor redução na cor do efluente e no teor de óleos e graxas. Comparando-se as figuras 3 e 4, nota-se a diferença do efluente bruto para o efluente tratado.

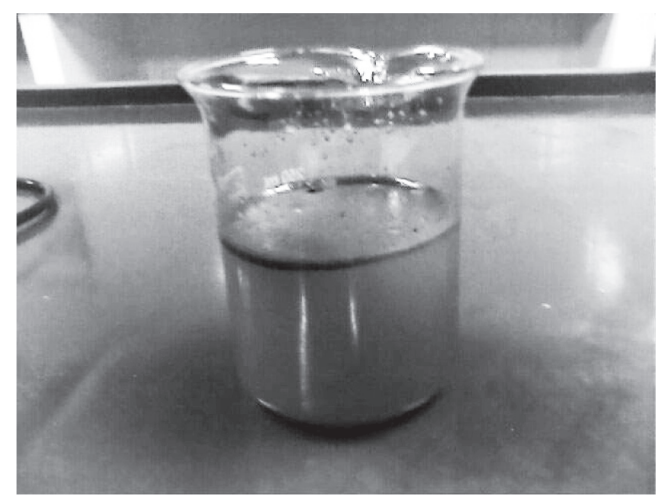

Figura 3

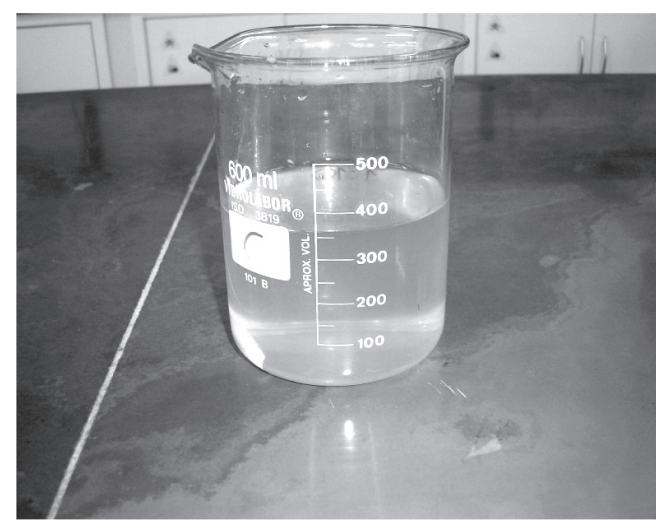

Figura 4

Apesar da melhor redução de matéria orgânica expressa em DQO tenha se dado no Teste $12(\mathrm{pH}=4,0$ peróxido de hidrogênio $350 \mathrm{mg} / \mathrm{L}$ e passagem pela câmara de UV), houve um aumento no parâmetro Cor da água.

Vale observar que todos os testes efetuados no efluente por processo oxidativo 
obtiveram resultados sempre abaixo dos valores especificados nos padrões de lançamento de efluentes, seja pela Resolução CONAMA 357-05, seja pela NT202 - R10.

A remoção da matéria orgânica recomendado pela resolução CONAMA $n^{\circ} 357$ 05 é de $80 \%$ mínimo em termos de DBO5, considerando que a DBO5 está contida na DQO na maioria dos efluentes, consideramos o parâmetro DQO para representar a remoção de matéria orgânica nos testes de bancada, o que demonstrou que todos os ensaios efetuados utilizando processos oxidativos, seja com ajuste de pH ou utilização da câmara de UV apresentaram remoção maior que $80 \%$ da matéria orgânica presente no efluente.

Vale salientar que se faz necessário a correção do $\mathrm{pH}$ do efluente para a faixa entre 6,0 e 8,0 para o reuso da água na lavagem dos veículos, visto que o melhor teste para a remoção da cor do efluente se deu em $\mathrm{pH}=2,0$.

\section{Referência Bibliográficas}

\section{AMERICAN PUBLIC HEALTH ASSOCIATION:}

Standard methods for the examination of water and wastewater. Prepared and published jointly by: APHA, AWWA and WPCF 14. ed. Washington, D.C., 1976. 847 p.

BARÊA, A, C e JARDIM, F, W: Processos Oxidativos Avançados Conceitos teóricos UNICAMP.

BERNARDO, L.: Ensaios de Tratabilidade de água e dos resíduos gerados em estações de tratamento de água. Rima. 2002

BERNARDO, Luiz Di; CENTURIONE FILHO, Paulo Luiz; ANGELA, DI BERNARDO. Ensaios de tratabilidade de água e dos resíduos gerados em estações de tratamento de água. São Carlos: RIMA, 2002. 237p

Chemical Analysis of Water Quality: Training Manual, EPA, Cincinnati, 1972.

FEEMA Manual do meio ambiente: métodos FEEMA. Rio de Janeiro; FEEMA; 1983. 499p
JORDAO, Eduardo Pacheco; PESSOA, Constantino Arruda. Tratamento de esgotos domésticos. 3. Rio de Janeiro: Abes, 1995. 720p.

MEES, B, J: Tratamento de Resíduos Líquidos III.

NETO, J.M.A. et alli (1998): Manual de hidráulica, Ed. Edgard Blücher Ltda., São Paulo.

RICHTER, Carlos A.; AZEVEDO NETTO, José M. De. Tratamento de água: tecnologia atualizada. São Paulo: Edgard Blücher, 2005. 332p. ISBN:8521200536. POLEZI, M.: Aplicação de Processos Oxidativo Avançado no Efluente de uma ETE para Fins de Reuso, 2003, Campinas/SP.

STRICKLAND J.D.H. and PARSONS T.R. A Pratical Handbook of Seawater Analysis, by. Ottawa 1972.

TASK GROUP REPORT: Charateristics and Effects of Synthetic Detergent - Journ. AW. W.A, 751, 1954.

UniFOA. Manual UniFOA para Elaboração de Trabalhos Téenicos. Volta Redonda. 2008.77p 
Anexo 1

\begin{tabular}{|c|c|c|c|c|c|c|c|c|c|}
\hline \multicolumn{10}{|c|}{ RESULTADOS OBTIDOS } \\
\hline \multirow{2}{*}{\multicolumn{3}{|c|}{ PARÂMETROS }} & DQO & $\mathrm{Fe}$ & OG & MBAS & $\mathrm{N}-\mathrm{NH} 3$ & COR & TURBIDEZ \\
\hline & & & $\mathrm{mg} / \mathrm{L}$ & $\mathrm{mg} / \mathrm{L}$ & $\mathrm{mg} / \mathrm{L}$ & $\mathrm{mg} / \mathrm{L}$ & $\mathrm{mg} / \mathrm{L}$ & Pt/Co & NTU \\
\hline \multirow{5}{*}{ ESPECIFICAÇÃO } & \multirow{4}{*}{ CONAMA 357-05 } & Classe I & - & 0,30 & Ausente & 0,50 & 3,70 & & 40,00 \\
\hline & & Classe II & - & 0,30 & Ausente & 0,50 & 3,70 & & 40,00 \\
\hline & & Classe III & - & 5,00 & Ausente & 0,50 & 13,30 & 75,00 & 100,00 \\
\hline & & $\begin{array}{l}\text { Lançamento de } \\
\text { Efluentes }\end{array}$ & - & 15,00 & 20,00 & & 20,00 & & - \\
\hline & \multicolumn{2}{|c|}{ NT202-R10 } & & 15,00 & 20,00 & 2,00 & 5,00 & Ausente & - \\
\hline & & & & & & & & & \\
\hline \multirow{14}{*}{ 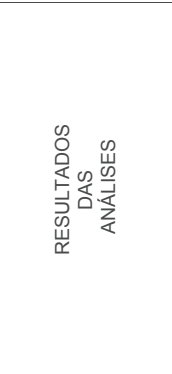 } & \multicolumn{2}{|l|}{ Amostra Bruta } & 12130,00 & 976,12 & 164,52 & 1,69 & 1,04 & 470,00 & 538,00 \\
\hline & \multicolumn{2}{|l|}{ Amostra Decantada } & 350,00 & 62,80 & 30,96 & 1,61 & 1,03 & 462,00 & 327,00 \\
\hline & \multicolumn{2}{|c|}{ Teste $1-\mathrm{pH} 7,0+\mathrm{H}_{2} \mathrm{O}_{2} 700 \mathrm{mg} / \mathrm{L}$} & 37,00 & 1,29 & 0,12 & 0,05 & 0,12 & 384,00 & 119,80 \\
\hline & \multicolumn{2}{|c|}{ Teste 2 - $\mathrm{pH} 7,0+\mathrm{H}_{2} \mathrm{O}_{2} 700 \mathrm{mg} / \mathrm{L}+\mathrm{UV}$} & 35,00 & 1,29 & 0,08 & 0,01 & 0,06 & 475,00 & 68,30 \\
\hline & \multicolumn{2}{|c|}{ Teste $3-\mathrm{pH} 2,0+\mathrm{H}_{2} \mathrm{O}_{2} 700 \mathrm{mg} / \mathrm{L}$} & 45,00 & 5,59 & 0,02 & 0,01 & 0,05 & 270,00 & 32,50 \\
\hline & \multicolumn{2}{|c|}{ Teste $4-\mathrm{pH} 2,0+\mathrm{H}_{2} \mathrm{O}_{2} 700 \mathrm{mg} / \mathrm{L}+\mathrm{UV}$} & 42,00 & 5,39 & $<0,01$ & $<0,01$ & 0,01 & 267,00 & 287,00 \\
\hline & \multicolumn{2}{|c|}{ Teste 5 - $\mathrm{pH} 4,0+\mathrm{H}_{2} \mathrm{O}_{2} 700 \mathrm{mg} / \mathrm{L}$} & 39,00 & 1,53 & 0,01 & 0,02 & 0,07 & 330,00 & 312,00 \\
\hline & \multicolumn{2}{|c|}{ Teste 6 - $\mathrm{pH} 4,0+\mathrm{H}_{2} \mathrm{O}_{2} 700 \mathrm{mg} / \mathrm{L}+\mathrm{UV}$} & 35,00 & 1,08 & $<0,01$ & $<0,01$ & 0,04 & 324,00 & 317,00 \\
\hline & \multicolumn{2}{|c|}{ Teste $7-\mathrm{pH} 7,0+\mathrm{H}_{2} \mathrm{O}_{2} 350 \mathrm{mg} / \mathrm{L}$} & 26,00 & 1,32 & 0,21 & 0,06 & 0,19 & 427,00 & 591,00 \\
\hline & \multicolumn{2}{|c|}{ Teste 8 - $\mathrm{pH} 7,0+\mathrm{H}_{2} \mathrm{O}_{2} 350 \mathrm{mg} / \mathrm{L}+\mathrm{UV}$} & 23,00 & 0,86 & 0,15 & 0,03 & 0,12 & 409,00 & 414,00 \\
\hline & \multicolumn{2}{|c|}{ Teste 9 - $\mathrm{pH} 2,0+\mathrm{H}_{2} \mathrm{O}_{2} 350 \mathrm{mg} / \mathrm{L}$} & 25,00 & 2,85 & 0,03 & 0,01 & 0,08 & 415,00 & 358,00 \\
\hline & \multicolumn{2}{|c|}{$\begin{array}{l}\text { Teste } 10-\mathrm{pH} 2,0+\mathrm{H}_{2} \mathrm{O}_{2} 350 \mathrm{mg} / \mathrm{L}+\mathrm{UV} \\
\text { Teste } 11-\mathrm{pH} 4.0+\mathrm{H}_{2} \mathrm{O}_{2} 350 \mathrm{mg} / \mathrm{L}\end{array}$} & 22,00 & 2,67 & $<0,01$ & $<0,01$ & 0,05 & 428,00 & 313,00 \\
\hline & \multirow{2}{*}{\multicolumn{2}{|c|}{$\begin{array}{l}\text { Teste } 11-\mathrm{pH} 4,0+\mathrm{H}_{2} \mathrm{O}_{2} 350 \mathrm{mg} / \mathrm{L} \\
\text { Teste } 12-\mathrm{pH} 4,0+\mathrm{H}_{2} \mathrm{O}_{2} 350 \mathrm{mg} / \mathrm{L}+\mathrm{UV}\end{array}$}} & 20,00 & 3,77 & 0,24 & 0,03 & 0,11 & 509,00 & 643,00 \\
\hline & & & 14,00 & 3,42 & 0,08 & $<0,01$ & 0,06 & 536,00 & 609,00 \\
\hline
\end{tabular}

\section{Endereço para Correspondência:}

Daniela V. Vasconcelos

Graduanda em Engenharia Ambiental- UniFOA

dani-vasconcelos@hotmail.com

Avenida Dezessete de Julho, nº 226 / apt 210

Aterrado - Volta Redonda - RJ

CEP: $27.213-200$

Informações bibliográficas:

Conforme a NBR 6023:2002 da Associação Brasileira de Normas Técnicas (ABNT), este texto científico publicado em periódico eletrônico deve ser citado da seguinte forma: VASCONCELOS, Daniela V.; GOMES, Anderson. Tratamento de efluentes de postos de combustíveis para o reúso usando processos oxidativos avançados. Cadernos UniFOA Volta Redonda, ano IV, n. 11, dezembro 2009. Disponível em: $<$ http://www.unifoa.edu.br/cadernos/edicao/11/35.pdf $>$ 